\title{
Psychological Features of the Pregnant Women Attitude to Motherhood in a Difficult Life Situation (COVID-19 Pandemic)
}

\author{
Margarita Shapovalova ${ }^{1},{ }^{*}$ Svetlana Niculina ${ }^{1}$, Elena Serdyukova ${ }^{2}$ \\ ${ }^{1}$ Pyatigorsk State University, Pyatigorsk, Russia \\ ${ }^{2}$ Chechen State University, Grozny, Russia \\ "Email: rey71@mail.ru
}

\begin{abstract}
The article reveals the psychological aspects of pregnant women's attitude to motherhood and their psychological support during pregnancy.

The conditions for the formation of an optimal attitude of a woman to her pregnancy due to its influence on the quality of her living, mastering the maternal role, the development of the maternal sphere, and the creation of an adequate system of interactions in the family after the birth of a child are substantiated.

The diagnostic tools are described, and the results of an experimental study aimed at studying the formation of an optimal value attitude to pregnancy and motherhood are presented.

The developed program "Comprehensive harmonious prenatal support for pregnant women" can be used in face-to-face work with pregnant women and a remote format. As already mentioned, its testing was carried out in the conditions of the COVID-19 pandemic. The evidence of its effectiveness was obtained after analysing the values of women's characteristics indicators during diagnostic sections by mathematical and statistical data analysis methods. Significant changes in their values indicate that this type of work is as effective as the traditional one.
\end{abstract}

Keywords: Pregnancy, Difficult life situation, Pregnancy experience, Mother-child dyad.

\section{INTRODUCTION}

Motherhood is a new stage in a woman's life. From the moment she realises her pregnancy, it becomes clear to a woman that her life has changed, and she will no longer be the same as she was before. Pregnancy is a crisis determined by the fact that a woman ceases to exist as a separate being, a mother-child dyad is born, and significant changes occur in her social life and activity.

Pregnancy sets goals and tasks for a woman that did not exist before, and an active personal restructuring is required to resolve them. She must accept the new role of a mother for her and learn to realise her needs, already considering the existence of a child in her life.

Adaptation to pregnancy occurs in different ways and depends on many factors. One of the most significant is the attitude to self-pregnancy and motherhood in general.
At the moment, it is vital to study the conditions under which a woman forms an optimal attitude to pregnancy and those factors that hinder the development of the optimal psychological type of gestational dominant (PTGD) [1]. It is essential to develop and implement programs that can be used to correct attitudes to her pregnancy, to the emerging mother-child dyad, and how a woman perceives society's attitude towards her. Work on correcting the type of relationship to pregnancy can and should be carried out during the psychological support of expectant mothers. Programs for childbirth preparation based on women's consultations are focused more on the medical part of the issue, leaving the critical psychological part aside. Specialists working individually or based on commercial organisations often do not consider the value-semantic changes in the consciousness of a pregnant woman. 
Modern achievements in medicine, physiology, gynaecology, obstetrics and paediatrics, improving the quality of specialist care for women during pregnancy, childbirth and after the birth of a baby, have helped solve many problems of motherhood and childhood. At the same time, psychological assistance to women, contributing to the correction of the types of PTGD that make it difficult for a woman to accept a maternal role, and the development of an optimal attitude to pregnancy and motherhood could prevent the appearance of many of them.

The conditions for the formation of an optimal attitude of a woman to her pregnancy due to the importance of this factor in the living of pregnancy, the development of the maternal sphere, mastering the maternal role and building an adequate system of interactions in the family after the birth of a child requires systematic experimental study [2].

The problems voiced in this study are rapidly developing today, has theoretical and practical developments in various branches of science and practice. The issue of relations was investigated in the framework of:

- a systematic approach to the study of personality psychology (Myasishchev V.N., Ananyev B.G., Lomov B.F., Rubinstein S.L.);

- theoretical and methodological provisions on motherhood and perinatal psychology (Dobryakov I.V., Meshcheryakova S.Yu., Filippova G.G., Avrutskaya V.V., Brutman V.I., Kopyl O.A., Vasilyeva V.V., Bas L.L., Bazhenova O.V.);

- age psychology (Vygotsky L.S., Leontiev A.N., Galperin P.Ya.).

However, even though the problem of a woman's attitude to her pregnancy has been studied for a long time, the need to monitor women's attitude to pregnancy remains relevant in the constantly changing conditions of social reality.

\section{RESEARCH METHODOLOGY}

The theoretical and methodological basis of the study are: a systematic approach Lomov B. F., Ananiev B.G., principles of the theory of systems of P.K. Anokhin, subject-activity approach Rubinstein S.L., the idea of the dominant Ukhtomsky, A.A., the concept of personality as a system of relations Myasishchev V.N.; the concept of motherhood in psychology [3, 4] (Brotman V.I., Filippov, G.G., Rama V.A., Samoukina N.V., Radionova M.S., Voronina O.R.), theoretical and applied research problems of mothers [5] (Filippova G.G, Brothman V.I., Khamitov I.Yu., Meshcheryakov S.Y., Misurova S.A., Teterleva E.A., Abramchenko V.V., Anokhin A.A., Bazhenova O.V., Baz L.L., Kopyl O.A., Beloborodov S., Shmakov Ch., Bergum V., Bloch M. E., Podobina O.B.,
Bratus V.I., Vasil'eva O.S., Mogilev E.V., Klochko Yu.N., Ermilova N.Yu., Klochko A., G.S. Kostyuk, Kochanova L.V., Novozhilov V.E., R.V. Ovcharova, Raploa E.A.); parent-child relationships in psychology $[6,7]$ (Varga A.Ya., Kamantauskas G.T., Eidemiller E.G., etc.).

\section{RESEARCH RESULTS}

The empirical study was conducted based on structural divisions of the SBHCI SR "Pyatigorsk interdistrict maternity hospital": women's consultation; centre for medical and social support of pregnant women in Pyatigorsk. The sample of subjects consisted of 60 pregnant women in the third trimester of pregnancy.

The study involved 60 pregnant women aged 21 to 36 years (average age 27.61 \pm 3.072 ) in the third trimester of pregnancy with different experiences of motherhood. The respondents were divided by randomisation into an experimental and control group of 30 people.

The main part of the subjects is primiparous. Their number was 46 people ( $80 \%$ of the total sample), 12 women are expecting 2 children (17.1\%), and 2 women are expecting 3 children ( $2.9 \%$ of the total sample).

The study included the following stages:

At the first stage, the goals and objectives of this study were determined, a theoretical analysis of the characteristics of personal changes in pregnant women was carried out based on the study of theoretical studies conducted within the framework of personality psychology, age psychology of development, age psychology and perinatal psychology.

At the second stage, psychological diagnostics, data processing and analysis were carried out to study the problem areas that occur in women during pregnancy. At this stage, a battery of psychodiagnostic techniques was used to comprehensively assess the targets of psychological support under the study's objectives.

A psychological support program "Comprehensive harmonious prenatal support for pregnant women" was developed at the third stage.

The fourth stage was devoted to a formative experiment, in which psychological support of pregnant women was organised in the experimental group with the help of a developed program. Following the program's results, diagnostics of the dynamics of changes in the identified problem areas was carried out to determine the program's effectiveness.

To carry out the diagnostic stage with pregnant women, the following psychological diagnostic techniques were used: 
1) Cattell's 16-factor personality questionnaire methodology for considering such qualities as anxiety, sensitivity, tension, etc.;

2) The scale of quantitative and qualitative assessment of the psychosomatic condition of pregnant women assessment by V.V. Abramchenko, T.A. Nemchin, with its help, we will get an assessment of the psychoemotional and somatic condition of a pregnant woman;

3) The "MADES (Methodology for assessing disease exposure and symptoms)" technique (a modified version for pregnant women) makes it possible to determine the severity of the impact of pregnancy on a woman and her symptoms, signs, as well as the influence of family and professional activities on the condition of a pregnant woman.

4) The PWA (the pregnant woman attitudes) test method is designed to determine the psychological component of the gestational dominant or the type of attitude to pregnancy in the expectant mother;

5) The colour test of attitudes by E.F. Bazhen, A.M. Etkind is designed to study the emotional components of personality attitudes;

6) Drawing test "Me and my child". The purpose of this diagnosis is to identify the peculiarities of the experience of pregnancy and the situation of motherhood, the perception of oneself and the child, the severity of the value of the child [4]

The study of the psychological characteristics of the attitude of pregnant women to motherhood involves a consistent diagnosis of the characteristics and determination of the parameters of adaptation to pregnancy and motherhood. We subjected the data obtained during the ascertaining and forming stages of the study to mathematical and statistical processing, using the Student's t-test method, which allows us to determine whether the average values of the indicators of the subjects of the compared groups and the Pearson correlation method differ significantly to see the relationship between the indicators of this study group [5]. The diagnostic stage of the study revealed certain conditions under which the development of an optimal attitude to pregnancy is difficult. A significant number of 36 women revealed the following: an idealised image of pregnancy, child and parenthood, rejection of their own body, changes and sensations occurring in it, a poorly formed idea of future motherhood and parental positions, a high level of anxiety, a weak awareness of responsibility for themselves and the child $[6,7]$.

\section{THE PROGRAM OF PSYCHOLOGICAL SUPPORT FOR PREGNANT WOMEN "COMPREHENSIVE HARMONIOUS PRENATAL SUPPORT FOR PREGNANT WOMEN"}

The program of psychological support proposed in this work involves the study of the main problems that arise during a woman's pregnancy, namely, psychological acceptance of physiological changes occurring in a pregnant woman; presentation of information about the peculiarities of pregnancy, childbirth, the postpartum period and motherhood; psychological assistance to a woman in adopting a new social role; assistance in stabilising the emotional state of a pregnant woman; as well as the elaboration of a system of value-semantic orientations of pregnant women to help increase the value of the child and motherhood in general [8].

The purpose of the program: the formation of an optimal attitude of a pregnant woman to the upcoming motherhood and the child.

\section{Program objectives:}

- formation of adequate ideas among the participants about the changes that occur with a woman during pregnancy and the postpartum period and acceptance of these changes;

- familiarity with the physiology of pregnancy, childbirth, the postpartum period; features of the intrauterine development of the child, the basics of the psychology of the early period of the child's life and the formation of attachment;

- formation of emotional self-regulation skills;

- formation of a realistic image of the unborn child and adequate forms of interaction with him;

- search for internal and external resources for the successful living of pregnancy and motherhood.

The program is designed for group work with pregnant women in the third trimester of pregnancy.

The main form of work is participation in a lesson on a given topic and developing practical skills during training exercises. Each lesson involves a homework assignment to help women integrate the information received and consolidate it at the operational level.

The program was implemented remotely, online (in the conditions of the COVID-19 pandemic to reduce the risks of morbidity of pregnant women and compliance with established norms at a given time), using the electronic ZOOM platform. The use of this platform enables live participation of all program participants simultaneously, the ability to view slides, presentations, ask questions, participate in discussions [9]. 
Table 1. Program summary "Comprehensive harmonious prenatal support for pregnant women"

\begin{tabular}{|c|c|}
\hline Lesson 1 & Content \\
\hline Informational lesson & $\begin{array}{l}\text { Purpose: to introduce, inform and educate pregnant women about pregnancy. } \\
\text { Tasks: acquaintance, establishing rules of communication in a new format, acquaintance } \\
\text { about the main aspects of pregnancy, studying the psychology of pregnancy. }\end{array}$ \\
\hline \multicolumn{2}{|l|}{ Lesson 2} \\
\hline Practical lesson & $\begin{array}{l}\text { Purpose: to increase the self-confidence and self-confidence of a pregnant woman. } \\
\text { Tasks: studying the spectrum of feelings, learning self-regulation methods, auto-training, } \\
\text { gymnastics, relaxation, deep diaphragmatic breathing. }\end{array}$ \\
\hline \multicolumn{2}{|l|}{ Lesson 3} \\
\hline Informational lesson & $\begin{array}{l}\text { Purpose: informing and educating pregnant women about childbirth, forming an active } \\
\text { position of a pregnant woman in childbirth. Formation of an optimal attitude to the process } \\
\text { of childbirth. } \\
\text { Tasks: to study the psychology of childbirth, the phase of childbirth, the psychology of pain } \\
\text { and methods of anaesthesia. }\end{array}$ \\
\hline \multicolumn{2}{|l|}{ Lesson 4} \\
\hline Practical lesson & $\begin{array}{l}\text { Purpose: to reduce the level of anxiety. } \\
\text { Tasks: using gymnastics, teaching relaxation techniques, studying the function of pain in } \\
\text { childbirth, training deep diaphragmatic breathing, using voice in childbirth, training } \\
\text { breathing during attempts. Watching the movie "Soft childbirth". }\end{array}$ \\
\hline \multicolumn{2}{|l|}{ Lesson 5} \\
\hline Informational lesson & $\begin{array}{l}\text { Purpose: to inform and educate pregnant women about postpartum depression. } \\
\text { Tasks: the study of depression, methods of self-regulation, art therapy, the study of } \\
\text { techniques for the development of self-awareness and the value-semantic sphere of } \\
\text { personality. }\end{array}$ \\
\hline \multicolumn{2}{|l|}{ Lesson 6} \\
\hline Practical lesson & $\begin{array}{l}\text { Purpose: prevention of depression, improvement of emotional background. } \\
\text { Tasks: stabilising the emotional sphere, forming constructive behavioural skills, and } \\
\text { studying cognitive restructuring techniques. Breathing training in attempts. Study of } \\
\text { relaxation methods. }\end{array}$ \\
\hline \multicolumn{2}{|l|}{ Lesson 7} \\
\hline Informational lesson & $\begin{array}{l}\text { Purpose: to inform about a new-born child's psychological and physiological characteristics. } \\
\text { Formation of an optimal attitude to interaction in the "mother-child" dyad. Formation of a } \\
\text { differentiated, realistic image of a child. } \\
\text { Tasks: a study of psychology, physiology of a new-born child. }\end{array}$ \\
\hline \multicolumn{2}{|l|}{ Lesson 8} \\
\hline Practical lesson & $\begin{array}{l}\text { Purpose: to inform about breastfeeding. Formation of an optimal attitude to interaction in } \\
\text { the "mother-child" dyad. } \\
\text { Tasks: study of feeding methods, gain knowledge about breastfeeding, the opportunity to } \\
\text { dispel myths about breastfeeding, create the mood of a pregnant woman to breastfeed a } \\
\text { child, }\end{array}$ \\
\hline \multicolumn{2}{|l|}{ Lesson 9} \\
\hline Practical lesson & $\begin{array}{l}\text { Purpose: summing up the course results. } \\
\text { Tasks: consolidation of the material covered, receiving feedback from participants (their } \\
\text { impression of the course as a whole), formation of positive attitudes. }\end{array}$ \\
\hline
\end{tabular}

The number of classes: nine classes (considering the physical characteristics of pregnant women, it is possible to vary the number of classes in the direction of their increase, reducing the time of one lesson), twice a week for one month (Table 1).

The duration of the lesson is 3 hours (180 minutes) with 2 breaks of 15 minutes. Contingent: pregnant women in the third trimester (28-30 weeks). The number of women in one group should not exceed 10 people.
Methods and techniques of work: emotionalcognitive therapy, rational therapy, art therapy, minilectures, training exercises, meditating, meditation, exercises, breathing techniques, discussion, and technology on the development of self-awareness and value-semantic sphere of the personality, the stabilisation of the emotional sphere and the formation of constructive behavioural skills, exercises, and equipment to the development of self-awareness and value-semantic sphere of personality [8]. 


\section{Structure of a typical lesson:}

The lesson begins with a greeting, which allows you to identify the format and topic of the meeting, set up the group members to work actively, create a favourable psychological climate. Then there is an exchange of messages about the situational representation of the participants of their thoughts, feelings and bodily sensations to realise the processes taking place. This technique allows you to listen to the body's sensations to understand the difference between thoughts and feelings.

The lesson continues with the help of thematic conversations, discussions, lectures, practical and training exercises, exercises for emotional consolidation of the results of the conversation, relaxation techniques. There are two breaks in the lesson.

The final part includes a reflection on the work done.

The effectiveness of the developed program is confirmed by the results of mathematical and statistical data processing. Before the formative stage of the study, there were no statistically significant differences between the values of indicators of the characteristics of pregnant women in the control and experimental groups. [10] Comparison of the values of the indicators using the Student's t-test after the formative stage of the study using the developed program "Comprehensive harmonious antenatal care for pregnant women" showed 26 statistically significant differences out of a possible 37 , which amounted to $70.2 \%$.

\section{CONCLUSION}

Diagnosis of the type of attitude to pregnancy showed a low percentage of women who have the optimal type of attitude to pregnancy. A significant number of women have ambivalent feelings about the appearance of motherhood. At the same time, the attitude towards pregnancy is not static and may change during the waiting period for the child.

Psychological support of pregnancy as per the developed program leads to a decrease in the severity of anxiety in most women; they gain calmness, readiness for many situations in the upcoming childbirth, and contact with the new-born baby.

The developed psychological support program for pregnant women contributes to forming an optimal value attitude to pregnancy and motherhood. The diagnostic stage of the study confirmed its effectiveness.

The developed program can be used in face-to-face work with pregnant women and a remote format. As already mentioned, its testing was carried out in the conditions of the COVID-19 pandemic. The evidence of its effectiveness was obtained after analysing the values of women's characteristics indicators during diagnostic sections by mathematical and statistical data analysis methods. Significant changes in their values indicate that this type of work is as effective as the traditional one. Using the program "Comprehensive harmonious prenatal support for pregnant women" in psychological assistance to pregnant women is possible with the help of modern video technologies remotely, for example, during a seasonal increase in the incidence of influenza and SARS to minimise risks. The remote format of the conducted program may allow women who have movement restrictions for some reason to participate in it, for example, women who need to observe bed rest for medical reasons.

\section{REFERENCES}

[1] I.V. Dobryakov, Perinatal Psychology [Perinatal'naya psihologiya], St. Petersburg: St. Petersburg, 2010, pp. 123-127.

[2] G.G. Filippova, Psychology of motherhood. Textbook [Psihologiya materinstva, Uchebnoe posobie], M: Publishing House of the Institute of Psychotherapy, 2002, pp.34-47.

[3] M.V. Kuzin, Embryonic pedagogy: games with an unborn baby [Embrional'naya pedagogika: igry s eshche ne rodivshimsya malyshom], Rostov n/A: Phoenix, 2007, From 87-96.

[4] M.L. Shapovalova, E.F. Serdyukova, Transformation of integral individuality of students with different ways out of difficult life situations. Scientific monograph [Transformaciya integral'noj individual'nosti studentov s raznymi sposobami vyhoda iz trudnyh zhiznennyh situacij. Nauchnaya monografiya], Grozny: ChSU, 2018, pp. 56-78.

[5] L.G. Skorobogatova, A book about harmonious pregnancy [Kniga o garmonichnoj beremennosti], St. Petersburg: U-Factoriya, 2006, pp. 23-41.

[6] I.A. Kolinichenko, Socio-psychological studies of personality identity and its relation to morality [Social'no-psihologicheskie issledovaniya identichnosti lichnosti i ee otnosheniya k morali] [Electronic resource]: monograph / I.A. Kolinichenko, S.A. Nikulina, Pyatigorsk: PSU, 2020, pp. 11-18.

[7] Finer Lawrence B., Stanley K. Henshaw, Disparities in Rates of Unintended Pregnancy in the United States, 1994, 2001. // Perspectives on Sexual and Reproductive Health, New York: Guttmacher Institute 38(2) (2006) 90-96.

[8] Frost Jennifer J., Susheela Singh, Lawrence B. Finer, US Women's One-Year Contraceptive Use Patterns, 2004 // Perspectives on Sexual and Reproductive Health, New York: Guttmacher Institute 39(1) (2007) 48-55. 
[9] N.A. Mitsyuk, The motherhood problem in modern foreign historical research [Problema materinstva $\mathrm{v}$ sovremennyh zarubezhnyh istoricheskih issledovaniyah] / Bulletin of TvSU, The series "History" [Vestnik TvGU. Seriya «Istoriya»] 2 (2015) 124-134. Retrieved from: https://core.ac.uk/download/pdf/74273593.pdf

[10] B. Finer Lawrence, K. Stanley, Henshaw, Disparities in Rates of Unintended Pregnancy In the United States, 1994, 2001 // Perspectives on Sexual and Reproductive Health, New York: Guttmacher Institute 38(2) (2006) 90-96. 